\title{
Peripheral and central components in variants of the Mueller-Lyer illusion
}

\author{
JOAN S. GIRGUS \\ The Cing College of the Cin Linersity of Vew York. Vew York. . Vew York 10031 \\ STANLEY COREN \\ The Graduate Facult?. . Vew School for Social Research. . Vew York. .Vew York 10011 \\ and \\ LEAH HOROWITZ \\ The City College of the City Lniversity of . Vew York, New York. New York 10031
}

\begin{abstract}
Illusion decrement with prolonged inspection was used as a technique to assess the relative amount of central component in seven variants of the Mueller-Lyer illusion. Results indicate that all of the variant forms share a common. central component. While the peripheral components. such as lateral inhibition. vary as a function of the presence of converging lines in the illusion configurations.
\end{abstract}

Most of the early research on visual geometric illusions was characterized by attempts to explain all illusions in terms of a single theory. Wundt (1897) used feedback from eye movements to explain these perceptual distortions. while Thiery $(1895.1896)$ used depth cues and Einthoven (1898) suggested that blurring of the retinal image was the basic mechanism for illusion formation. As evidence began to accumulate. however. it became clear that most visual geometric illusions are multiply caused and contain a variety of peripheral and central components (Coren \& Girgus. 1972). Among the suggested peripheral contributions to illusion magnitude. we find degradation of the image due to diffraction and optical aberrations in the ere (Chiang. 1968). Coren (1969) has shown that this source of distortion can account for some $15 \%$ of the Poggendorff illusion. Békésy (1967) and Ganz (1966) have presented evidence that suggests that lateral inhibition operating on converging or intersecting line elements adds to the magnitude of many illusions. Coren (1970) has shown that when possible sources of inhibitory interactions are removed. the magnitude of the distortion contained in some illusions is greatly reduced, although some illusory effects still remain. A number of central components have also been identified. Gillam (1971) and Gregory (1963) have shown that perspective cues which evoke constancy scaling mechanisms play a part in illusion formation. while Coren (1971). Girgus. Coren. and Agdern (1972). Massaro and Anderson (1971). Pressey (1967). and Restle and Merryman (1968) have all presented data which suggest the operation of comparative judgmental components in illusion formation.

It should be clear that not all illusion configurations will manifest significant proportions of all of these contributory factors. Some illusions should have large peripheral components. while some should be predominantly central in origin. It would be extremely valuable if one could assess the relative contribution of the peripheral and the central components in any given illusion. One possible technique to effect such a measure involves illusion decrement.

Since the pioneer work of Judd (1902). many investigators have demonstrated that visual illusions diminish in magnitude with inspection. This decrement with prolonged viewing has been repeatedly confirmed for the Mueller-Lyer illusion (Day. 1962: Dewar. 1967: Köhler \& Fishback. 1950: Lewis. 1908; Mountjoy. 1960) and has also been demonstrated in the Poggendorff. Zoellner. and Wundt-Hering illusions (Cameron \& Steele. 1905: Coren \& Girgus. 1972: Judd \& Courten, 1905). Although the mechanisms for this decrease in illusion magnitude with free viewing are not fully understood. it seems likely that it reflects some form of central judgmental reorganization of the percept. This impression is supported by at least three lines of evidence: (1) the effects of decrement persist and are cumulative over dav's or weeks (Judd. 1902): (2) rate of decrement responds to traditional learning variables such as the spacing of trials (Dewar. 1968: Mountioy. 1958): and (3) the amount of decrement is increased if information about the nature and extent of the illusion is made available through information feedback from erroneous eye movements over the figure (Coren \& Hoenig. 1972: Festinger. White. \& Allyn. 1968: Hoenig. 1972).

It seems unlikely that the proposed peripheral components which may be involved in the formation of the geometric illusions. such as lateral inhibition on the retina (Békésy. 196\%: Coren. 1970: Ganz. 1966). distortions due to optical aberrations (Chiang. 1968: Coren. 1969). or density of the macular pisment 


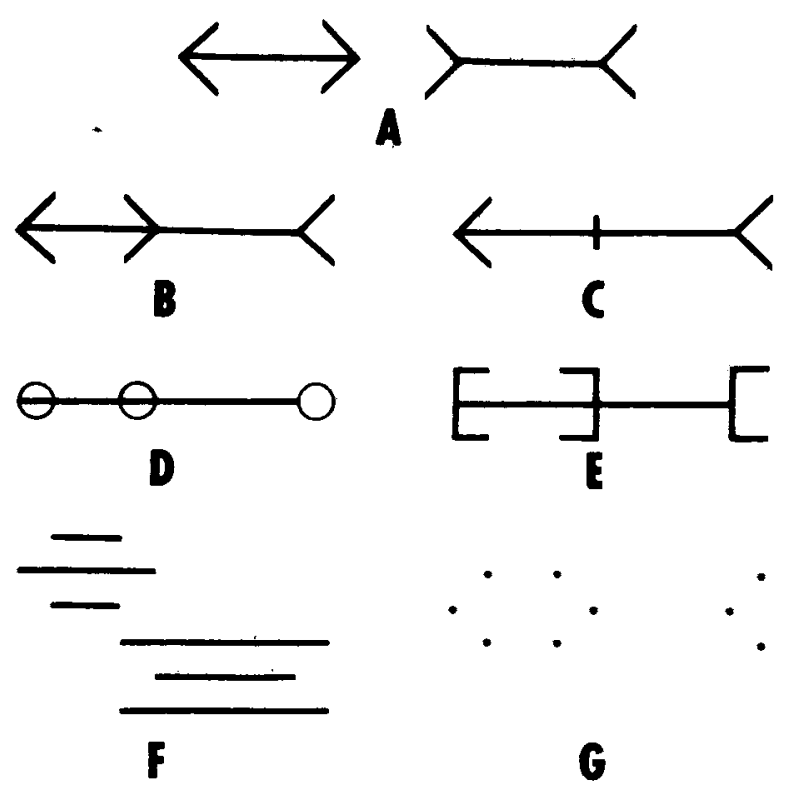

Fig. 1. The variants of the Mueller-Lyer illusion used in this experiment: (A) the standard separated form, (B) the Brentano form. (C) the Judd form. (D) the circle form, (E) the square wing form, (F) the Piaget form, and (G) the Coren form.

(Pollack \& Silvar, 1967), would be expected to respond in this manner to practice with the illusion configurations. This would imply that the amount of initial illusion that disappears as the result of prolonged viewing of the figures might serve as an index of the amount of central relative to the amount of peripheral involvement in various illusion figures. An illusion with a large peripheral component would be expected to decrease very little over time. while an illusion with a large central component would be expected to decrease nearly to zero.

In light of these speculations, let us consider a specific set of illusions. such as the Mueller-Lyer and its variants. This illusion has been presented in many forms. some of which involve converging lines and some of which do not. Since converging or intersecting lines provide the optimal conditions for the operation of peripheral interactions such as lateral inhibition or optical aberrations (Coren. 1969, 1970). we would expect maximal illusion in configurations containing these elements. Despite the increased illusion magnitude, however, we would expect the rate and amount of illusion decrement to remain unchanged, since decrement presumably operates only upon the central component of the distortion. In addition. if such a result is found. it would seem to verify the usefulness of illusion decrement as a measure of the amount of central vs peripheral involvement in the formation of specific illusions. Thus, the following experiment examines the effect of prolonged free viewing on various forms of the Mueller-Lyer illusion.

\section{METHOD}

\section{Subjects}

Seventy undergraduate volunteers served as Ss. Each was assigned randomly to one of seven different forms of the Mueller-Lyer illusion.

\section{Stimuli}

The stimuli used in this experiment were the seven variants of the Mueller-Lver figure shown in Fig. 1. The standard separated form is Fig. 1A. and the configuration introduced by Brentano (1892) is Fig. 1B. A variant introduced by Judd (1899) appears in $\mathrm{Fig} .1 \mathrm{C}$. These three variants all contain converging lines and thus should optimize the effects of peripheral factors such as lateral inhibition and optical aberrations. An intermediate degree of line convergence is shown in Fig. 1D. Here, the curved portions. of the circles which intersect the horizontal shafts should approximate the straight converging lines of Figs. 1A, 1B, and $1 C$. Three forms with no converging lines were also used. The first is a squared off version of the Brentano form of the illusion depicted in Fig. IE. A form with no intersecting lines introduced by Piaget (1969) is depicted in Fig. IF. The last configuration used is a dot form ( $F$ ig. $1 G$ ), which was introduced by Coren (1970) and is specifically designed to minimize the possibility of peripheral interactions by the elimination of adjacent converging contours

All the figures were constructed with 1-mm-wide black lines ( $6 \sigma_{c}$ reflectance) on a background of $80 \%$ reflectance. The test shafts were $8 \mathrm{~cm}$ long. When angles were present. they were $45 \mathrm{deg}$ from the horizontal. For each configuration. the apparently longer half of the illusion figure was made adjustable through the use of a tongue and groove arrangement. Readings were taken in millimeters from a scale affixed to the back of the adjustable length. The stimulus was viewed at a distance of $45 \mathrm{~cm}$.

\section{Procedure}

All Ss made an initial setting of apparent equality between the two segments of the figure. This was followed by a 5-min inspection period with free eve movements. Additional measures of illusion magnitude were taken at 1 -min intervals throughout the inspection period.

\section{RESULTS AND DISCUSSION}

Figure 2 shows the results of this experiment. It is clear that the initial magnitude of the illusion varied as a function of the degree of line convergence in the various configurations. Illusion forms which contain a greater proportion of converging lines. and thus more opportunity for peripheral interactions. show the greatest initial magnitude $(F=21.92 . \mathrm{df}=6 / 63$. $\mathrm{p}<.01)$.

The critical comparisons involve the rate and extent of illusion decrement with inspection. As can be seen in Fig. 2. all seven forms of the Mueller-Lver used in this study diminished at approximately the same rate over the 5 -min inspection period. This is statistically. confirmed by an analysis of variance performed on these data. The effects of illusion figure and practice are both significant $(F=42.52 . \mathrm{dt}=6,63 . p<01$. and $F=$ 91.00. $\mathrm{df}=5 / 315 . \mathrm{p}<.01$. respectively): the interaction between illusion figure and judgments is. however. not significant $\left(\mathrm{F}=1.3 \overline{3}\right.$. $\mathrm{df}=30^{\prime} 315$. n.s.). One might argue that the test for a significant interaction is not a very 
sensitive measure. We therefore computed the best fit regression line for each decrement curve. The obtained slopes of the regression lines of illusion magnitude in millimeters plotted against time in minutes varied over a range of only 0.06 , and none of the 21 possible paired differences was statistically significant. This result may be taken as additional support for the similarity in the rate of decrement among the various illusion configurations. ${ }^{1,2} \mathrm{It}$ is clear from the lack of significant interaction and the initial difference in illusion strength that at the end of the inspection period the various illusion forms showed different amounts of residual illusion. This residual illusion may be taken as an indication of the size of the peripheral contribution to the illusion.

In summary, the similarities in the slopes of the decrement curves suggest that all of the variants of the Mueller-Lyer used in this study have a common underlying central component that is subject to recalibration during inspection with free eye movements. The various amounts of illusion in the different figures, both before and after the inspection period, suggests various amounts of a peripheral component (or components) present in the different forms. Measured in this way, the amount of peripheral component present seems to correspond with the presence or absence of converging lines in the figure.

Although we have suggested that decrement consists of a central, cognitive recalibration, it should be noted that it has been suggested by other authors that these central processes are physiological rather than judgmental. Thus, Köhler and Fishback (1950) have proposed that decrement occurs through the operation of satiation of cortical fields, and Coltheart (1971), in analyzing aftereffects of tilt and curvature, has suggested the operation of the adaptation of specific cortical feature analyzers which might cause a shift in the apparent locus of a contour. The cortical satiation hypothesis is easily discarded on the basis of the present data, since it would predict maximal satiation in regions bounded by converging lines and hence more decrement for the four variants that provide converging lines than for the three variants that do not. The adaptation of specific feature analyzers only seems to predict in cases of tilt or of relative direction of lines. Thus, this theoretical position could not predict the large decrement obtained for the Piaget form (Fig. IF) or the Coren form (Fig. 1G), since the former contains only parallel horizontal lines and the latter contains no lines at all. Another possible explanation could be offered, based on speculation that lateral inhibition is not exclusively a retinal phenomenon, as we have been suggesting. It seems reasonable to suggest that neurons interact in excitatory or inhibitory fashions throughout the visual system. If these hypothesized interactions can be modified by prolonged stimulation, it might account for the obtained decrement in illusion magnitude. This hypothesis implies. however, that the maximal

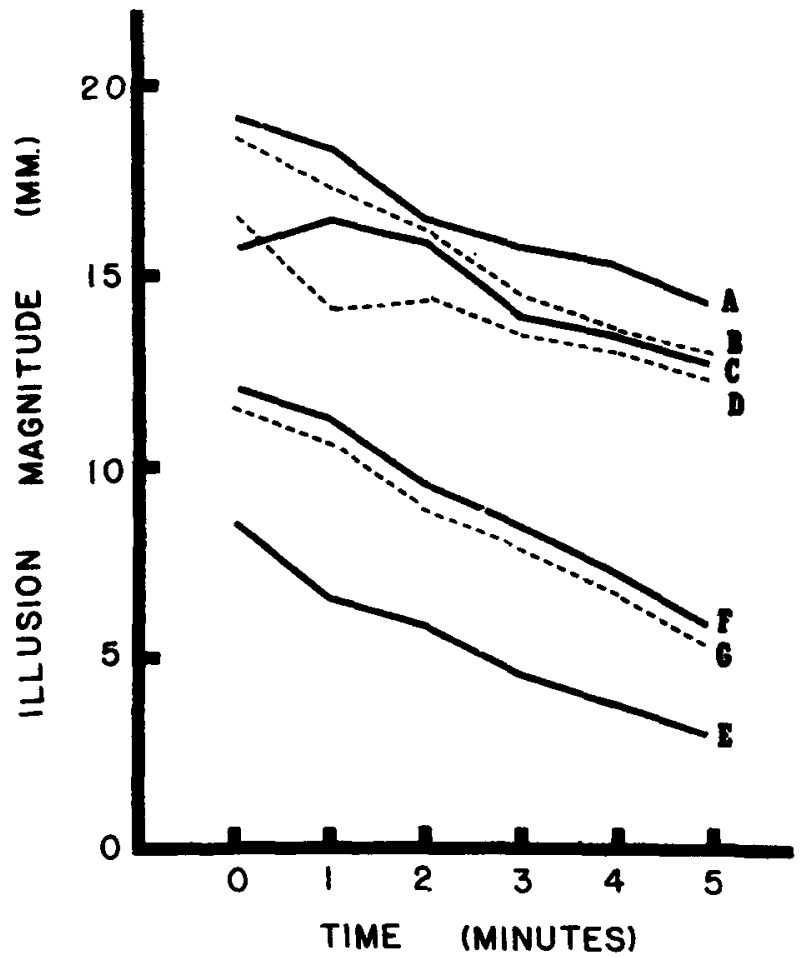

Fig. 2. The magnitude of the illusion in millimeters plotted as a function of viewing time for each of the illusion variants. Letters indicate the illusion form used as labeled in Fig. 1.

decrement would be found in illusory configurations where lines converge, thus providing the optimal conditions for interactions. However, as we have demonstrated above, there is no evidence of any slope differences:

The data presented here seem to suggest a convenient method for establishing the relative contribution of peripheral and central components in illusions. A purely peripherally caused distortion should show no decrement at all with inspection, while a purely judgmental effect should decrement to zero with adequate inspection time. It would be a simple matter to extend the inspection period to the point where the amount of decrement had clearly reached asymptote, in order to provide an absolute measure of the amount of an illusory distortion which is due to peripheral components. The decrement technique is not capable of allowing us to isolate specific peripheral or central components as it now stands; however, it does provide a convenient index of the relative contribution of these classes of factors to the formation of the perceptual distortion in visual geometric illusions.

\section{REFERENCES}

Békésy, G. von. Sensory imhibition. Princeton: Princeton University Press. 1967.

Brentano, i: ̈̈ber cin optiscles Paradoson. Zeitschrift für Puchologic. 1892. 3. 349-358. 
Cameron, E. H., \& Steele. W. M. The Poggendorff illusion. Psychological Review Monograph Suplement, 1905, 7 (No. 29), 83-111.

Chiang, C. A. A new theory to explain geometrical illusions produced by crossing lines. Perception \& Psychophysics, $1968,3,174-176$.

Coltheart, M. Visual feature-analyzers and aftereffects of tilt and curvature. Psychological Revtew. 1971,78, 114-121.

Coren. S. The influence of optical aberrations on the magnitude of the Poggendorff illusion. Perception \& Psychophysics. 1969.6. $18 \mathrm{j}-186$.

Coren. S. Lateral inhibition and geometric illusions. Quarterly Journal of Experimental Psychology, 1970, 22, 274-278.

Coren, S. A size contrast illusion without physical size difference. American Journal of Psychology, 1971, 84, $565-566$.

Coren, S., \& Girgus,..J. S. Illusion decrement in inter'secting line figures. Psychonomic Science, 1972, 26, 108-110.

Coren, S.,-\& Girgus, J. S. Visual spatial illusions: Many explanations. Science, 1972, in press.

Coren. S., \& Hoenig, P. Eye movements and decrement in the Oppel-Kundt illusion. Perception \& Psychophysics, 1972, 12, 224-225.

Day, R. H. The effects of repeated trials and prolonged fixation on error in the Muller-Lyer figure. Psychological Monographs, $1962,76(14$, Whole No. 533).

Dewar, R. E. Stimulus determinants of the practice decrement of the Mueller-Lyer illusion. Canadian Journal of Psychology, 1967, 21, 504-520.

Dewar, R. E. Distribution of practice and the Muller-Lyer illusion. Perception \& Psychophysics, 1968, 3, 246-248.

Einthoven. W. Eine einfache physiologische Erklärung für verschiedene geometrisch-optische Täuschungen. Pflüger's Archiv für Physiologie, 1898, 71, 1-43.

Festinger, L., White, C. W., \& Allyn, M. R. Eye movements and decrement in the Müller-Lyer illusion. Perception \& Psychophysics, 1968, 3, 376-382.

Ganz, L. Mechanism of the figural aftereffects. Psychological Review, 1966, 73, 128-150.

Gillam, B. A depth processing theory of the Poggendorff illusion. Perception \& Psychophysics, 1971, 10, 211-216.

Girgus, J. S., Coren, S., \& Agdern, M. The interrelationship between the Ebbinghaus and Delboeuf illusions. Journal of Experimental Psychology, 1972, 95, 453-455.

Gregory, R. L. Distortion of visual space as inappropriate constancy scaling. Nature (London), 1963, 199, 678-679.

Hoenig, $P$. The effects of eye movements, fixation and figure size on decrement in the Müller-Lyer illusion. Unpublished doctoral dissertation, New School for Social Research, 1972.
Judd, C. H. A study of geometrical illusions. Psychological Review, 1899, 6, 241-262.

Judd, C. H. Practice and its effects on the perception of illusions. Psychological Review, 1902, 9, 27-39.

Judd, C. H., \& Courten, H. C. The Zoellner illusion. Psychological Review, 1905, 7, 83-111.

Köhler, W., \& Fishback, J. The destruction of the Müller-Lyer illusion in repeated trials: I. An examination of two theories. Journal of Experimental Psychology, 1950, 40; 267-281.

Lewis, E. O. The effect of practice on the perception of the Müller-Lyer illusion. British Journal of Psychology, 1908, 2, 294-306.

Massaro, D. W., \& Anderson, N. H. Judgmental model of the Ebbinghaus illusion. Journal of Experimental Psychology, $1971,89,147-151$.

Mountjoy, P. T. Effects of exposure time and intertrial interval upon deciement to the Müller-Lyer illusion. Jouinal of Experimental Psychology, 1958, 56, 97-102.

Mountjoy, P. T. Fixation and decrement to the Muller-Lyer figure. Psychological Record, 1960, 10, 219-223.

Piaget, J. The mechanisms of perception. (Trans. G. N. Seagrim) New York: Basic Books, 1969.

Pollack, R. H., \& Silvar, S. Magnitude of the Mueller-Lyer illusion in children as a function of pigmentation of the Fundus oculi. Psychonomic Science, 1967, 8, 83-84.

Pressey, A. W. A theory of the Mueller-Lyer illusion. Perceptual \& Motor Skills, 1967, 25, 569-572.

Restle, F., \& Merryman, C. T. An adaptation-level theory account of a relative-size illusion. Psychonomic Science, 1968, 12, 229-230.

Thiery, A. Über geometrische-optische Täuschungen. Philosophische Studien, 1895-1896, 12, 67-126.

Wundt, W. Outlines of psychology. (Trans. C. H. Judd) Leipzig: W. Engelmann, 1897.

\section{NOTES}

1. We would like to thank Raymond Pass for his assistance in the statistical analysis of these data.

2. As a further post hoc analysis, we calculated the combined regression coefficient of the three apparently flattest curves (A, $B$, and $C$ ) and compared it to the combined regression coefficient of the two apparently steepest curves ( $F$ and $G$ ). Even this stringent post hoc comparison, with its increased probability of rejecting the null hypothesis, failed to yield a significant interaction $(z=0.96)$.

(Received for publication July 10, 1972; revision accepted November 1,1972 .) 